\title{
APLIKASI SISTEM PAKAR PENGEMBANGAN POTENSI KECERDASAN PADA ANAK USIA DINI BERBASIS WEB DENGAN METODE FORWARD CHAINING
}

\author{
Nanda Jarti' ${ }^{1)}$, Arwin ${ }^{2)}$ \\ ${ }^{1,2)}$ Fakultas Teknik Universitas Putera Batam \\ Email : nandaluthan@gmail.com \\ Submitted: 02-01-2018, Reviewed: 06-01-2018, Accepted 10-01-2018 \\ http://dx.doi.org/10.22202/jei.2017.v4i2.2792
}

\begin{abstract}
Early Childhood Education is very important because intelligence and the foundations of a person's behavior that are formed at an early age so that this age is often called the golden age. Every child has potential, but that potential can only thrive when given a stimulus, guidance, support, and treatment in accordance with the level of growth and development. There are at least eight potential intelligence contained in children. Therefore, the importance of the knowledge of parents and people around the see the potential of intelligence found in children, especially young children. An expert system is a computerbased application that is used to solve the problem, as is thought by experts. Application Intelligence Expert System Development potential in early childhood is built using the programming language PHP, HTML, CSS and MySQL as database storage. In this expert system used forward chaining method, where the process starts by selecting the facts by answering questions True (yes) or False (not) displayed the system. The output of this system in the form of potential intelligence contained in children and solution development. There are 10 potential intelligence that can be detected in this expert system. The benefits derived from this expert system can provide insights for parents and people around the see the potential contained in early childhood and development solutions without having to deal directly with the experts.
\end{abstract}

Keywords: Childhood, forward chaining, Potential Intelligence, Expert System

\begin{abstract}
Abstrak
Pendidikan Anak Usia Dini sangat penting karena potensi kecerdasan dan dasar-dasar perilaku seseorang yang terbentuk pada usia dini sehingga usia ini sering disebut usia golden age. Setiap anak memiliki potensi, tetapi potensi tersebut hanya dapat berkembang manakala diberi rangsangan,
\end{abstract}

53 Diterbitkan Oleh Program Studi Pendidikan Informatika STKIP PGRI Sumbar 
bimbingan, bantuan, dan perlakuan sesuai dengan tingkat pertumbuhan dan perkembangannya. Sedikitnya terdapat 8 potensi kecerdasan yang terdapat pada anak. Oleh karena itu, pentingnya pengetahuan orang tua dan orang sekitar dalam melihat potensi kecerdasan yang terdapat pada anak khususnya anak usia dini. Sistem pakar adalah aplikasi berbasis komputer yang digunakan untuk menyelesaikan masalah sebagaimana yang dipikirkan oleh pakar. Aplikasi Sistem Pakar Pengembangan potensi Kecerdasan Pada Anak Usia Dini Ini dibangun dengan menggunakan bahasa pemrograman PHP, HTML, CSS dan MySQL sebagai penyimpanan database. Pada sistem pakar ini menggunakan Metode Forward Chaining, dimana proses dimulai dengan memilih fakta-fakta dengan menjawab pertanyaan Benar (ya) atau Salah (tidak) yang ditampilkan sistem. Keluaran dari sistem ini berupa potensi kecerdasan yang terdapat pada anak dan solusi pengembangannya. Terdapat 10 potensi kecerdasan yang dapat dideteksi pada sistem pakar ini. Manfaat yang diperoleh dari sistem pakar ini dapat memberikan pengetahuan bagi orang tua dan orang sekitar dalam melihat potensi yang terdapat pada anak usia dini dan solusi pengembangannya tanpa harus berhadapan langsung dengan pakar.

Kata Kunci: Anak Usia Dini, forward chaining, Potensi Kecerdasan, Sistem Pakar

\section{PENDAHULUAN}

Untuk menciptakan generasi yang berkualitas, pendidikan harus dilakukan sejak usia dini. Pendidikan Anak Usia Dini (PAUD) yaitu pendidikan yang dilakukan sejak lahir sampai usia 6 tahun. Pendidikan Anak Usia Dini (PAUD) sangat penting karena potensi kecerdasan dan dasar-dasar perilaku seseorang yang terbentuk pada usia dini sehingga usia ini sering disebut usia golden age. Perkembangan yang diperoleh pada usia dini, sangat mempengaruhi perkembangan anak pada tahap berikutnya dan meningkatkan produktivitas kerja dimasa dewasa. Setiap anak memiliki potensi, tetapi potensi tersebut hanya dapat berkembang manakala diberi rangsangan, bimbingan, bantuan, dan perlakuan sesuai dengan tingkat pertumbuhan dan perkembangannya. Oleh karena itu sekolah, guru, lingkungan keluarga, dan orang tua juga memainkan peranan penting dalam tumbuh kembang anak.Dari hasil pengamatan penulis khusunya kehidupan masyarakat di Kota Batam sebagai kota industri, yang penduduknya didominasi para pekerja dengan usia produktif, membuat kehidupan masyarakat dikota Batam memiliki mobilitas yang sangat tinggi. Hal ini dapat menyebabkan kurangnya pengetahuan orang tua dalam melihat dan mengembangkan potensi kecerdasan yang dimiliki anaknya, Dengan adanya kemajuan teknologi yang semakin pesat, telah berkembang suatu teknologi yang mampu mengadopsi dan cara pikir manusia yaitu kecerdasan buatan atau Artificial Intellegence (AI). Dengan adanya 
kecerdasan buatan, komputer akan dapat membantu menyelesaikan masalah yang besar dan kompleks dengan lebih cepat dan objektif dari manusia.

\section{LANDASAN TEORI}

\section{Artificial Intelligent}

Menurut Suyanto (2014:11) para ilmuan memiliki dua cara pandang yang berbeda tentang AI. Yang pertama memandang AI sebagai bidang ilmu yang hanya fokus pada proses berpikir. Sedangkan yang ke dua memadang AI sebagai bidang ilmu yang fokus pada tingkah laku. Cara pandang ke dua melihat AI secara lebih luas karena suatu tingkah laku pastilah didahului proses pikir. Defenisi yang paling tepat untuk saat ini adalah acting rationally dengan pendekatan rational agent. Hal ini berdasarkan pemikiran bahwa komputer bisa melakukan penalaran secara logis dan juga bisa melakukan aksi secara rasional berdasarkan hasil penalaran tersebut.

Kecerdasan Buatan (Artificial Intelligence atau AI) didefenisikan sebagai kecerdasan entitas alami. Sistem seperti ini pada umumnya dianggap komputer. Kecerdasan diciptakan dan dimasukkan ke dalam suatu mesin (komputer) agar dapat melakukan pekerjaan seperti yang dapat dilakukan manusia. Beberapa macam bidang yang menggunakan kecerdasan buatan antara lain sistem pakar, permainan komputer (games) logika fuzzy, jaringan syaraf tiruan dan robotika (Husda, 2012:192) Sistem PakarMenurut Kusrini (2008:3) Sistem Pakar adalah aplikasi berbasis komputer yang digunakan untuk menyelesaikan masalah sebagaimana yang dipikirkan oleh pakar. Ada 2 metode inferensi yang penting dalam sistem pakar yaitu: runut maju (forward chaining) dan runut balik (backward chaining).Menurut Hayadi (2016: 1) sistem pakar atau expert system biasa disebut juga dengan Knowledge Base System yaitu suatu aplikasi computer yang ditujukan untuk membantu pengambilan keputusan atau memecahkan persoalan dalam bidang yang spesifik. Sistem ini bekerja dengan menggunakan pengetahuan dan metode analisis yang telah didefenisikan terlebih dahulu oleh pakar yang sesuai dengan bidang keahliannya. Sistem ini disebut sistem pakar karena fungsi dan peranannya sama seperti orang seorang ahli yang harus memiliki pengetahuan, pengalaman dalam memecahkan masalah suatu persoalan.

Pengertian Sistem Pakar Menurut Beberapa Ahli:Arhami (2004) dalam Hayadi (2016: 2) Sistem Pakar adalah cabang dari AI yang membuat penggunaan secara luas Knowledge yang khusus untuk menyelesaikan masalah tingkat manusia yang pakar.Siswanto (2010) dalam Hayadi (2016: 2) Sistem pakar adalah suatu cabang dari Artificial Intelligence (AI) yang cukup tua karena sistem ini mulai 


\section{Jurnal Edik Informatika \\ E-ISSN : 2541-3716}

Penelitian Bidang Komputer Sains dan Pendidikan Informatika

V4.i2(53-71) 2018

dikembangkan pada tahun 1960. Sistem pakar adalah program $A I$ dengan basis pengetahuan (Knowledge Base) yang diperoleh dari pengalaman atau pengetahuan pakar atau ahli dalam memecahkan persoalan pada bidang tertentu dan didukung mesin
Interensi/Inferensi Engine yang melakukan penalaran atau pelacakan terhadap sesuatu atau fakta-fakta dan aturan kaidah yang ada dibasis pengetahuan setelah dilakukan pencarian sehingga dicapai kesimpulan.
Lingkungan Konsultasi

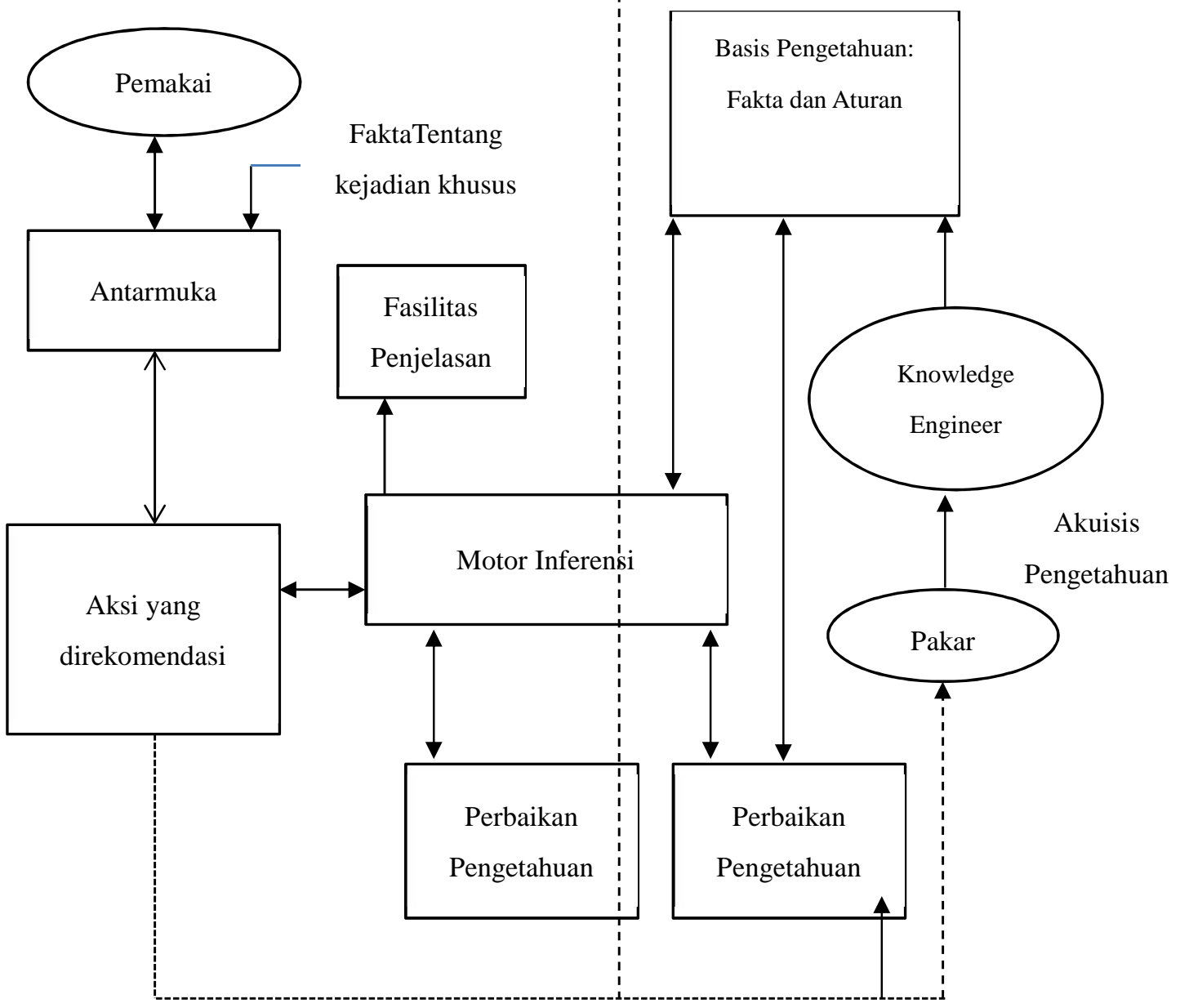

\section{Gambar 1.}




\section{METODE PENELITIAN}

\section{Desain Penelitian}

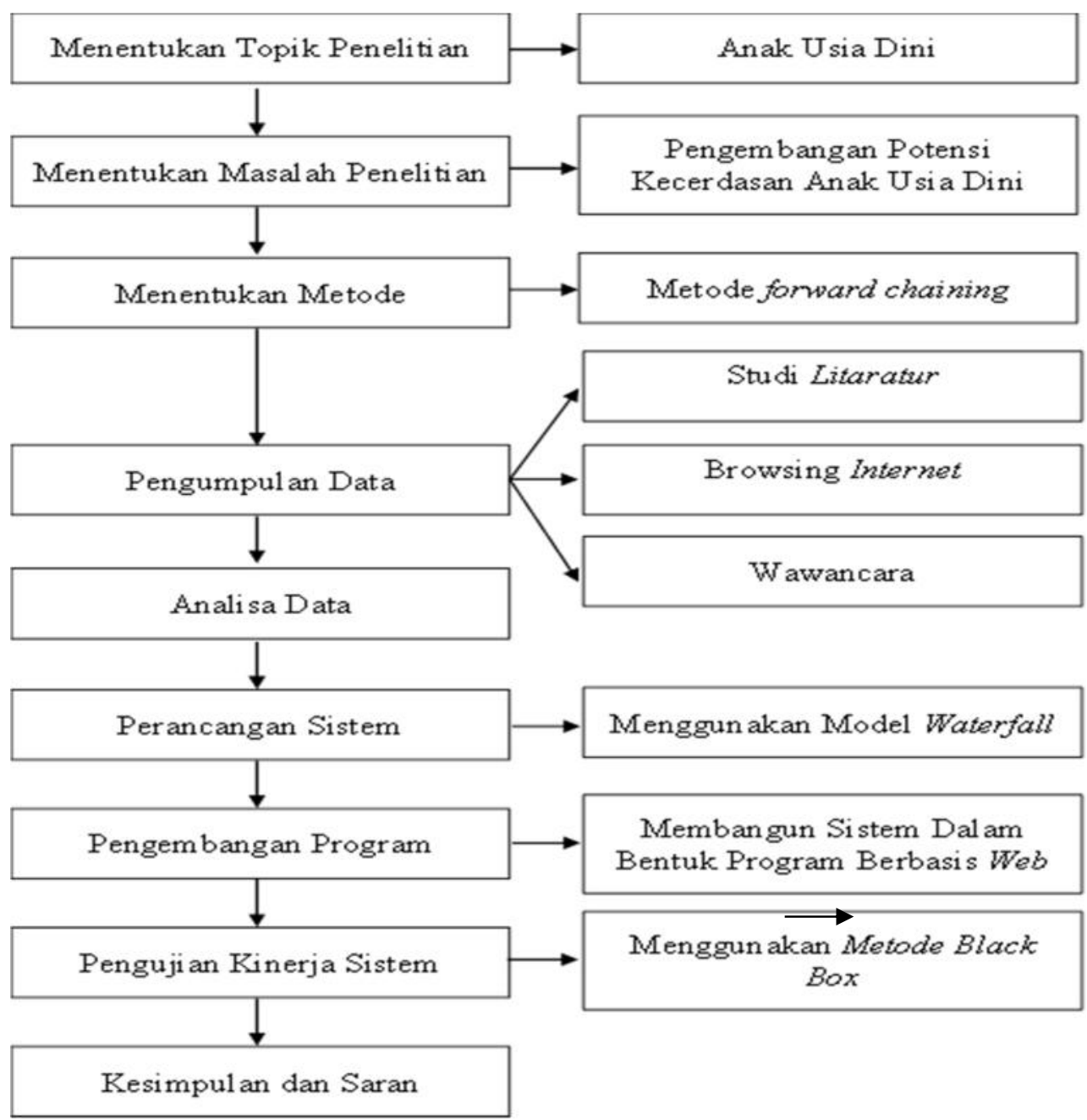

\section{Gambar 2.}

1. Menentukan Topik Penelitian

Langkah pertama pada desain penelitian adalah dengan memilih topik penulis mengambil topik tentang "Anak Usia Dini”.
2. Menetukan Masalah Peneitian

Setelah topik ditentukan, langkah selanjutnya menentukan masalah yang akan menjadi penelitian. Penulis melakukan penelitian tentang 
"Pengembangan Potensi Kecerdasan Pada Anak Usia Dini”.

3. Menetukan Metode

Sistem Pakar pada Tugas Akhir/Skripsi ini, penulis menggunakan metode forward Chaining. Dimana Metode Forward Chaining merupakan penalaran dimulai dari fakta-fakta terlebih dahulu untuk menguji kebenaran hipotesis.

4. Pengumpulan Data

Langkah selanjutnya adalah metode yang berhubungan dengan pengumpulan data, pertama penulis mencari dan mempelajari sumber-sumber pengetahuan berupa buku, jurnal, dan sumber pustaka lainnya yang berhubungan dengan topik penelitian penulis diperpustakaan dan beberapa toko buku. Kedua penulis browsing di internet untuk mencari sumber pustaka lainnya berupa e-book yang memiliki ISBN dan juga membeli buku melalui toko buku online. Ketiga penulis melakukan wawancara kepada pihak yang memiliki kompetensi dalam pengembangan potensi kecerdasan pada anak usia dini (pakar).

\section{Analisa Data}

Setelah data mengenai pengembangan potensi kecerdasan anak usia dini terkumpul, penulis melakukan analisa data dengan menyederhanakan dan mengelompokkan data tersebut agar lebih mudah dilakukan proses pengolahan datanya.

6. Pengembangan Sistem

Langkah selanjutnya adalah pengembangan sistem, ada beberapa model pengembangan perangkat lunak atau sering disebut SDLC (Software Development Life Cycle). Pada Tugas Akhir/Skripsi ini penulis menggunakan Model Waterfall. Model SDLC air terjun (Waterfall) sering juga disebut model sekuensial linier (sequensial linear) atau alur hidup klasik (classic life cycle).

7. Pengembangan Program

Tahap pengembangan program adalah tahap membangun sebuah sistem pakar berbasis web. Adapun bahasa pemrograman yang penulis gunakan adalah PHP, HTML,CSS, MySQL dan software pendukung lainnya.

8. Pengujian Kinerja Sistem

Langkah selanjutnya adalah melakukan pengujian kinerja sistem. Pada Tugas Akhir/Skripsi ini pendekatan yang dilakukan untuk melakukan pengujian adalah pendekatan Black-Box Testing (pengujian kotak hitam), yaitu menguji perangkat lunak dari segi spesifikasi fungsional tanpa menguji desain dan kode program. Pengujian dimaksud untuk mengetahui apakah fungsi-fungsi, masukan, dan keluaran dari perangkat 
lunak sesuai dengan spesifikasi yang dibutuhkan.

9. Kesimpulan dan Saran

Tahap terakhir dalam desain penelitian ini adalah menyimpulkan apakah Aplikasi Sistem Pakar yang telah dibuat dapat menjawab rumusan masalah yang telah dibuat sebelumnya pada BAB I. Penulis juga memberikan beberapa saran yang berhubungan dengan Tugas Akhir/Skripsi agar dapat dikembangakan dengan menggunakan metode yang berbeda.

\section{Operasional Variabel}

Menurut Zainal A. Hasibuan (2007:130) Variabel adalah sesuatu yang akan menjadi objek atau sering juga sebagai faktor yang berperan dalam peristiwa atau gejala yang akan diteliti. Ada beberapa variabel-variabel yang berkaitan dengan penelitian ini sebagai berikut :

\section{Tabel 3.1 Operasional Variabel}

\begin{tabular}{ll}
\hline Variabel & \multicolumn{2}{l}{ Indikator } \\
\hline & 1. KecerdasanLogis Matematis \\
Potensi & \multicolumn{2}{c}{ Berpikir } \\
Kecerdasan & \\
\cline { 2 - 2 } Pada Anak & 2. Kecerdasan Logis Matematis \\
Usia Dini & Angka \\
\cline { 2 - 2 } & 3. Kecerdasan Linguistik \\
\hline
\end{tabular}

\begin{tabular}{l} 
4. Kecerdasan Spasial \\
\hline 5. Kecerdasan Kinestetik \\
\hline 6. Kecerdasan Musik \\
\hline 7. Kecerdasan Interpersonal \\
\hline 8. Kecerdasan Intrapersonal \\
\hline 9. Kecerdasan Natural \\
\hline 10. Kecerdasan Spiritual
\end{tabular}

Sumber: Data Penelitian, 2017

Berdasarkan data aturan yang telah disusun, maka kaidah (rule) yang akan digunakan dalam sistem pakar adalah sebagai berikut:

1. Kaidah 1: IF KK01 AND KK02 AND KK03 AND KK04 AND KK05 THEN IK01

2. Kaidah 2: IF KK01 AND KK02 AND KK03 AND KK06 AND KK07 THEN IK02

3. Kaidah 3: $I F$ KK01 AND KK08 AND KK09 AND KK10 THEN IK03

4. Kaidah 4: IF KK01 AND KK02 AND KK11 AND KK12 THEN IK04

5. Kaidah 5: IF KK13 AND KK14 AND KK15 AND KK16 THEN IK05

6. Kaidah 6: $I F$ KK17 AND KK18 AND KK19 AND KK20 THEN IK06

7. Kaidah 7: IF KK21 AND KK22 AND KK23 AND KK24 THEN IK07

8. Kaidah 8:IF KK25 AND KK26 AND KK27 AND KK28 AND KK29 THEN IK08 
9. Kaidah 9: IF KK30 AND KK31 AND KK32 AND KK33 THEN IK09

10. Kaidah 10: IF KK21 AND KK34 AND KK35 AND KK36 THEN IK10

Berdasarkan kaidah (rule) yang telah dibuat maka dapat dijelaskan bahwa:

Kaidah 1: IF Dapat menentukan Pola Gambar yang saling bersesuaian AND imajinatif, suka memunculkan ide-ide yang unik AND mengetahui benda yang hilang jika ditunjukkan sesuatu yang belum sempurna / janggal AND suka bermain catur AND Suka membuat simbol untuk menjelaskan suatu benda THEN Kecerdasan Logis Matematis Berpikir.

Kaidah 2: IF Dapat menentukan pola gambar yang saling bersesuaian AND Imajinatif, suka memunculkan ide-ide yang unik AND Mengetahui benda yang hilang jika ditunjukkan sesuatu yang belum sempurna/janggal AND Suka mengerjakan operasi bilangan matematika dan Suka menghitung benda-benda disekitarnya THEN Kecerdasan Logis Matematis Angka.
Kaidah 3: IF Dapat menentukan pola gambar yang saling bersesuaian AND Imajinatif, Suka menulis dan membaca AND Suka berdiskusi dan berdebad terhadap suatu objek AND Mampu mengeja kata dengan tepat dan mudah, dan memiliki kosata kata yang baik dalam berkomunikasi THEN Kecerdasan Linguistik.

Kaidah 4: IF Dapat menentukan pola gambar yang saling bersesuaian AND Imajinatif, suka memunculkan ide-ide yang unik AND Dapat memanipulasi sebuah bentuk atau objek menjadi menarik AND Memiliki kemampuan menggambar (melukis) yang baik THEN Kecerdasan Spasial.

Kaidah 5: IF Tidak senang diam, merasa gelisah ketika harus duduk lama AND Suka membongkar mainan dan benda lain AND Senang berolah raga atau menari AND Pintar meniru gerakan orang lain, dan gemar menyentuk benda yang baru THEN Kecerdasan Kinestetik.

Kaidah 6: IF Senang bernyanyi dan bisa memainkan alat musik AND Mempunyai suara merdu dan dapat bernyanyi dengan nada yang tepat AND Bersemangat 
ketika belajar sambil mendengar musik AND Dapat menciptakan nada baru dengan menggunakan alat musik THEN Kecerdasan Musik.

Kaidah 7: IF Mempunyai perhatian yang tinggi kepada orang lain Suka memberi bantuan kepada temannya AND Menjadi anggota suatu kelompok dan Berani menjadi pemimpin AND Suka mengajari temannya tentang sesuatu AND Mudah bergaul dan disukai teman-temannya THEN Kecerdasan Interpersonal.

Kaidah 8: IF Mampu bersikap mandiri AND Suka menyebutkan citacitanya dan Mempunyai kemauan yang keras AND Tidak mudah stress dan panik terhadap suatu masalah AND Tak mengalami masalah jika harus belajar atau bermain sendiri AND Mempunyai karakter dan kebiasaan tersendiri THEN Kecerdasan Intrapersonal.
Kaidah 9: IF Suka memperhatikan fenomena alam AND Suka menanam tanaman, memihara hewan dan mengenali sifat dan tingkah lakunya AND Suka diajak kepantai dan kebun binatang AND Senang kegiatan diluar (alam) THEN Kecerdasan Natural

Kaidah 10: IF Mempunyai perhatian yang tinggi kepada orang lain dan Suka memberi bantuan kepada temannya AND Taat beribadah cepat menghafal ayat pada kitab suci dan melakukan kegiatan amal AND Suka mengajak orang lain berbuat kebaikan AND Taat dan patuh kepada perintah orang tua THEN Kecerdasan Spiritual

Berdasarkan kaidah yang telah dibuat terebut maka tabel keputusannya adalah sebagai berikut:

Tabel 3.6 Tabel Keputusan

\begin{tabular}{|c|c|c|c|c|c|c|c|c|c|c|}
\hline \multirow{2}{*}{$\begin{array}{l}\text { Indikator } \\
\text { Kecerdasa }\end{array}$} & \multicolumn{10}{|c|}{ Karakter Anak } \\
\hline & IK00 & IK00 & IK00 & IK00 & IK00 & IK00 & IK00 & IK00 & IK00 & IK1 \\
\hline $\mathrm{n}$ & 1 & 2 & 3 & 4 & 5 & 6 & 7 & 8 & 9 & 0 \\
\hline KK01 & $\sqrt{ }$ & $\sqrt{ }$ & $\sqrt{ }$ & $\sqrt{ }$ & & & & & & \\
\hline KK02 & $\sqrt{ }$ & $\sqrt{ }$ & & $\sqrt{ }$ & & & & & & \\
\hline KK03 & $\sqrt{ }$ & $\sqrt{ }$ & & & & & & & & \\
\hline
\end{tabular}




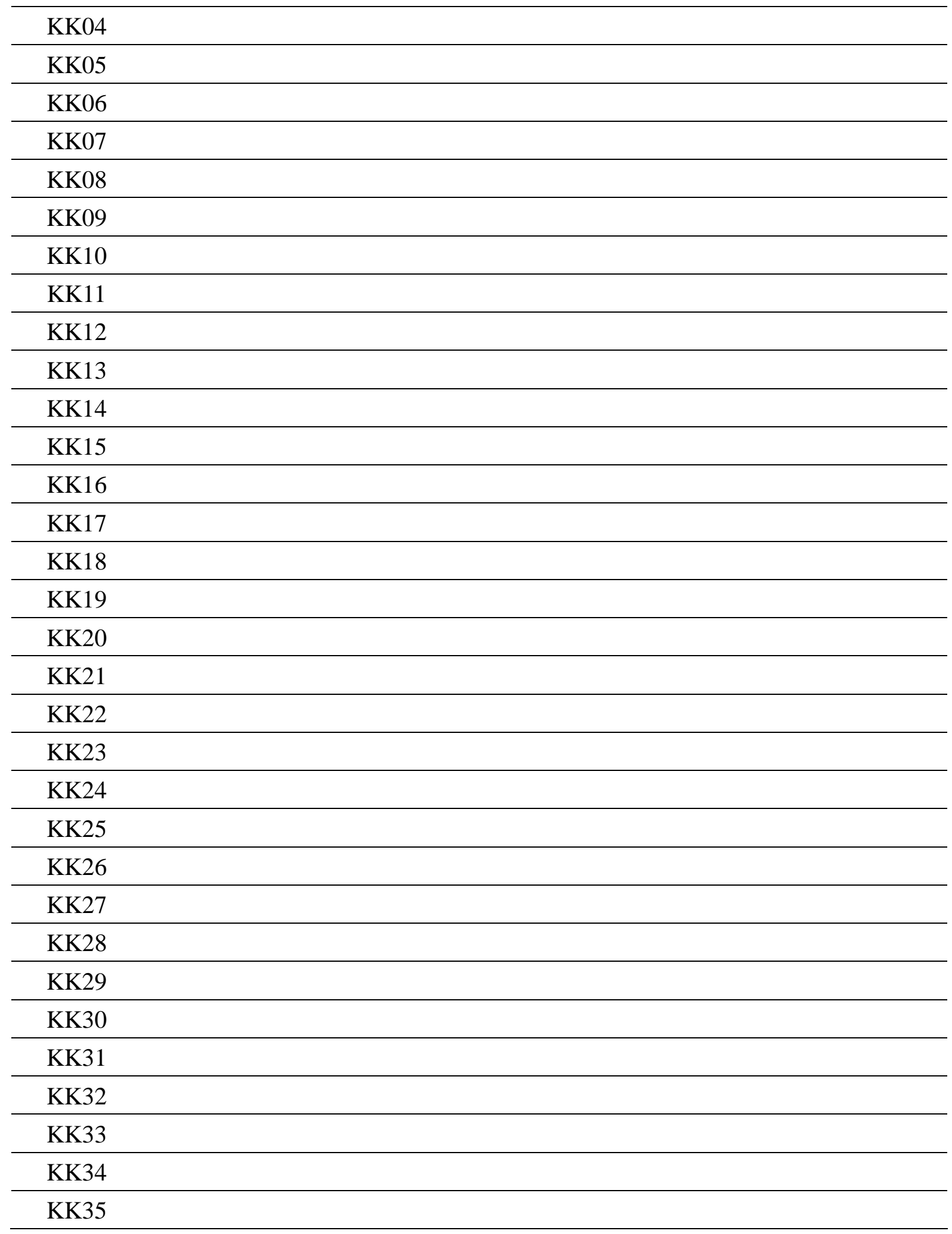

62 Diterbitkan Oleh Program Studi Pendidikan Informatika STKIP PGRI Sumbar 


\section{KK36}

Sumber: Data Penelitian, 2017

Berdasarkan tabel keputusan diatas maka pohon keputusannya adalah sebagai berikut:

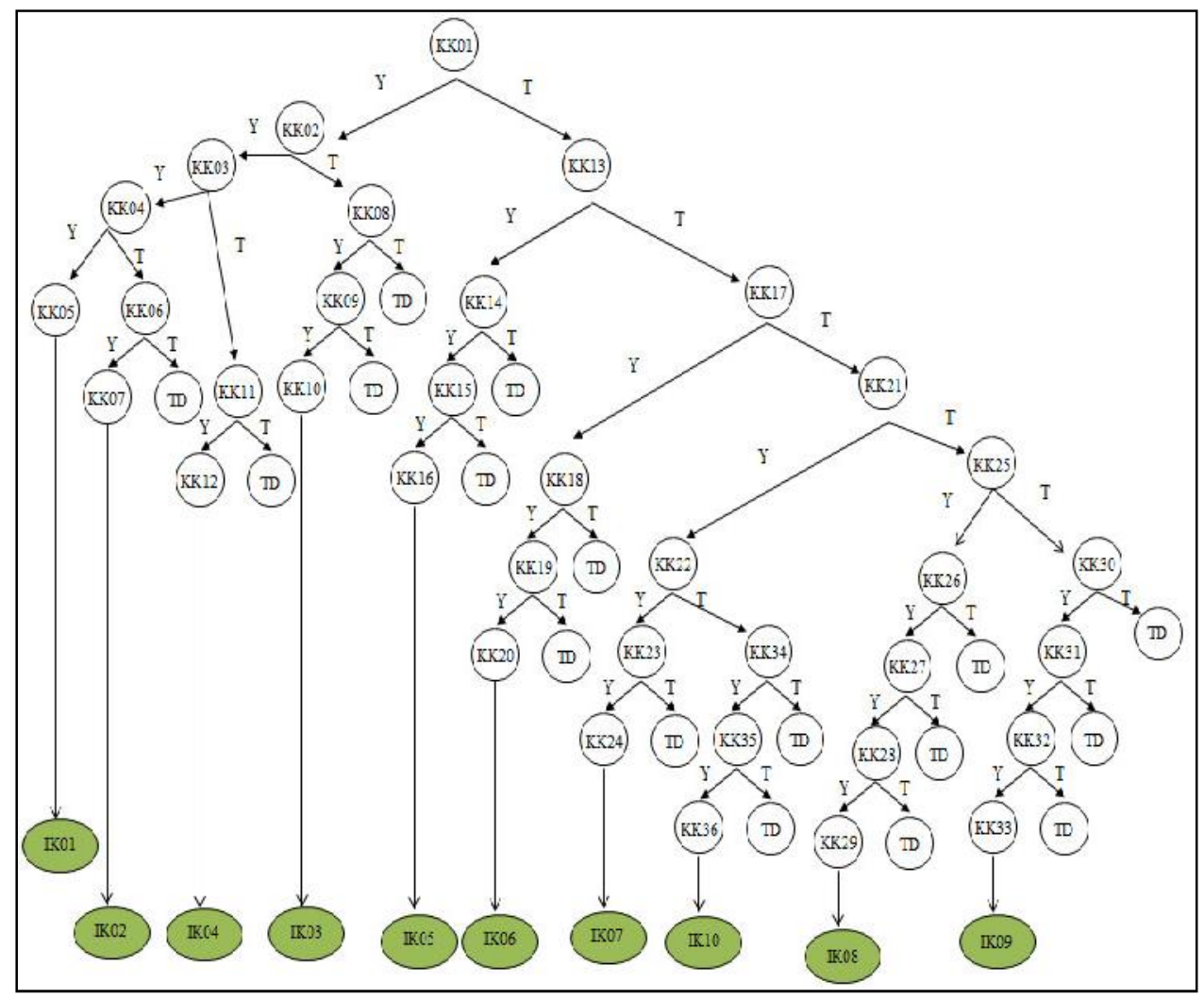

Gambar 3.3. Pohon Keputusan

Sumber: Data Penelitian, 2017

\section{Perancangan Sistem}

Perancangan sistem adalah mendesain atau merancang suatu sistem, yang berisikan langkah-langkah pengolahan data untuk mendukung suatu sistem. Dalam penelitian ini membahas mengenai perancangan basis pengetahuan (Knowledge Base), UML (Unified Modeling Language), dan Prototype Web.

\section{Use Case Diagram}


Use case pada Aplikasi Sistem Pakar ini dibuat untuk mendeskripsikan interaksi antara aktor dengan sistem pakar yang akan dibuat. Pada Sistem Pakar tugas Akhir/Skripsi ini aktor yang digunakan terdiri dari 2 orang, yaitu administrator dan user. Administrator adalah penulis sendiri sedangkan yang berperan sebagai User adalah orang tua, guru paud atau masyarakat.

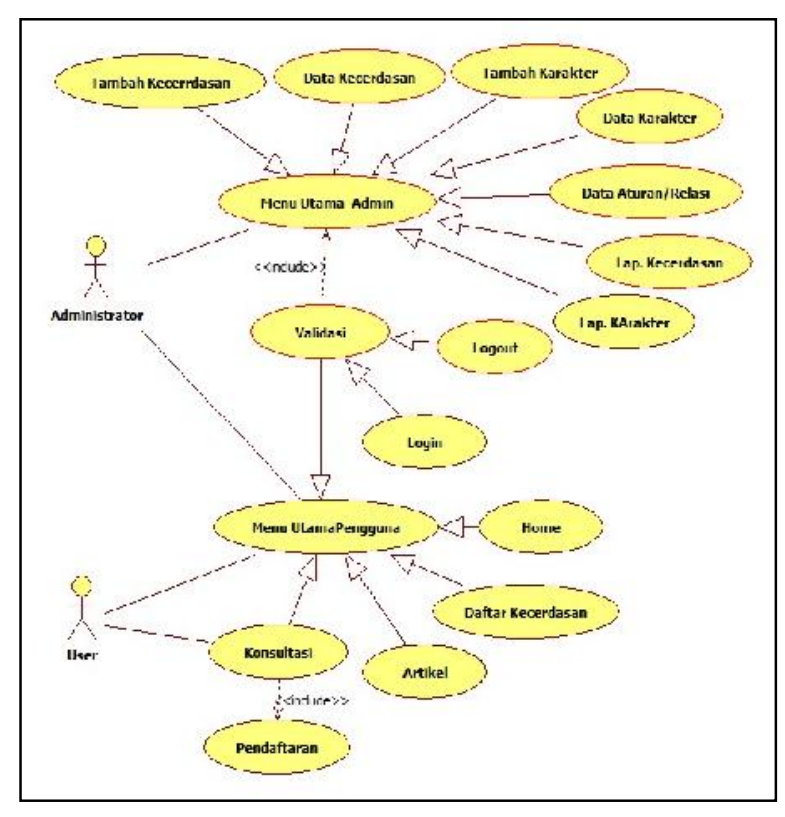

Gambar.

\section{Activity Diagram Data Kecerdasan}

Data Indikator Kecerdasan bertujuan agar admin dapat melakukan manipulasi (hapus, ubah, tambah) pada data Indikator Kecerdasan pada Aplikasi Sistem Pakar
Pengembangan Potensi Kecerdasan Pada Anak Usia Dini.

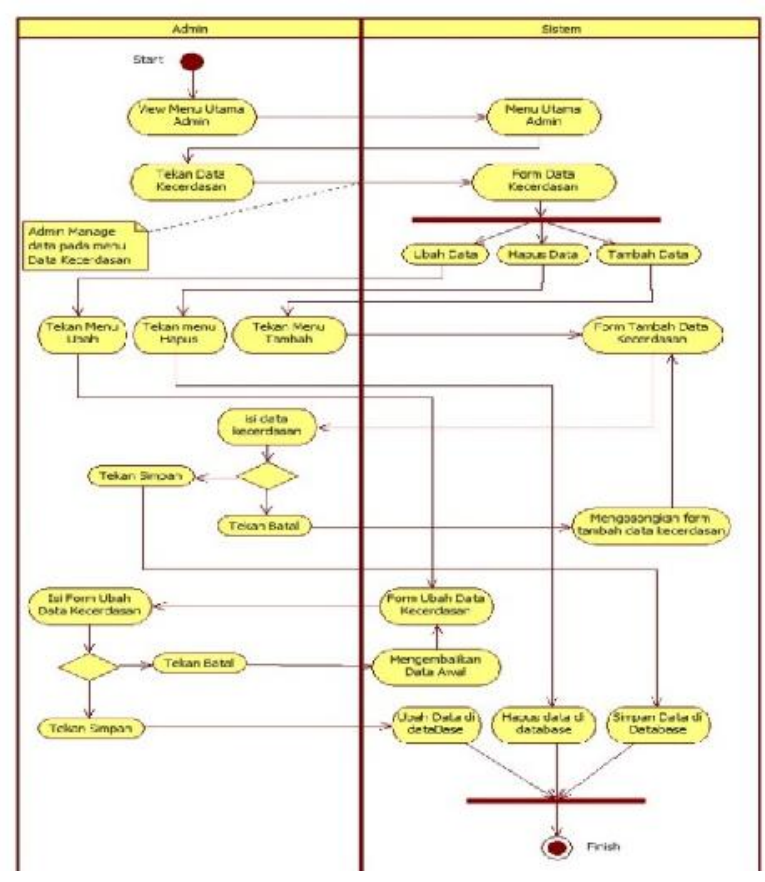

Gambar.

\section{HASIL DAN PEMBAHASAN}

\section{Hasil Penelitian}

Hasil Penelitian ini berupa Sistem Pakar berbasis web dengan MySQL sebagai penyimpan datanya yang didesain berdasarkan peran pengguna yaitu admin yang memilki wewenang dalam mengelolan content, serta user yang akan menggunakan sistem ini untuk melakukan konsultasi pengembangan potensi kecerdasan pada anak usia dini. Proses inferensi yang digunakan adalah pelacakan ke depan (forward chainng). 
Menu Utama Pengguna adalah menu utama yang akan muncul pertama kali pengguna mengakses sistem. Halaman ini berisi menu-menu yang menuju kehalaman berikutnya.

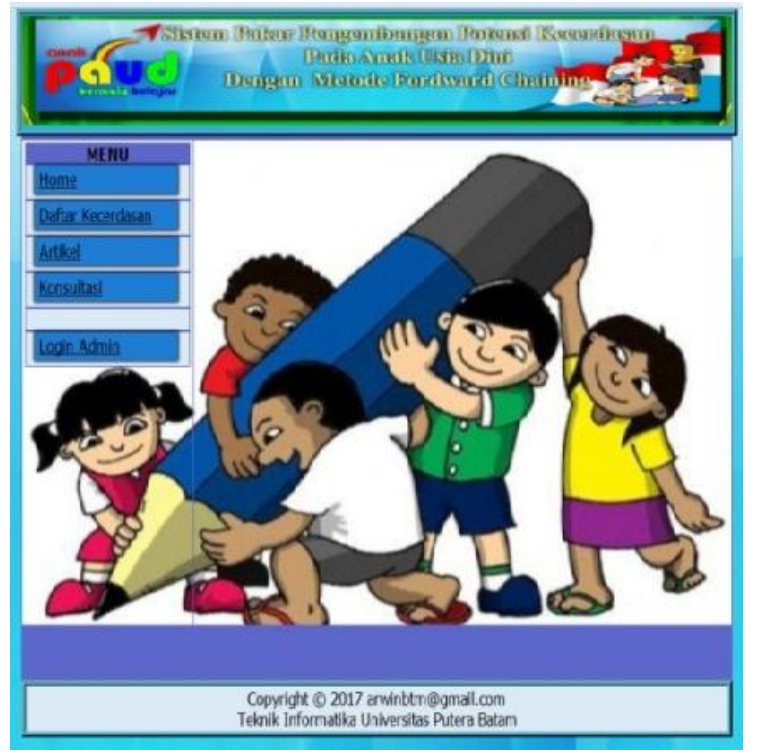

Gambar 4.1. Menu Utama Sistem

\section{Menu Home}

Didalam menu home terdapat $3 \mathrm{Tab}$ didalamnya. Tab 1 akan menjelaskan sistem yang sedang diaskes oleh pengguna, Tab 2 tentang profil pembuat sistem dan Tab 3 tentang petunjuk penggunaan sistem.

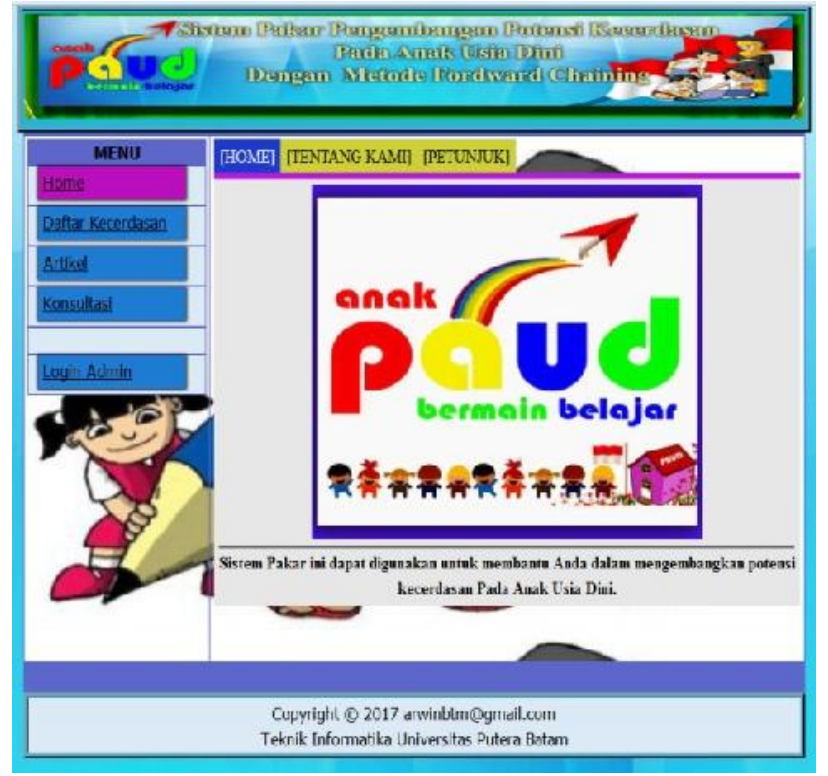

\section{Gambar.}

\section{Menu Daftar Kecerdasan}

Menu Daftar Kecerdasan berisikan informasi awal kepada user tentang potensi kecerdasan yang terdapat dalam sistem ini. User juga dapat melihat karakter yang mewakili potensi kecerdasan tersebut. 


\section{Jurnal Edik Informatika \\ E-ISSN : 2541-3716}

Penelitian Bidang Komputer Sains dan Pendidikan Informatika

V4.i2(53-71) 2018

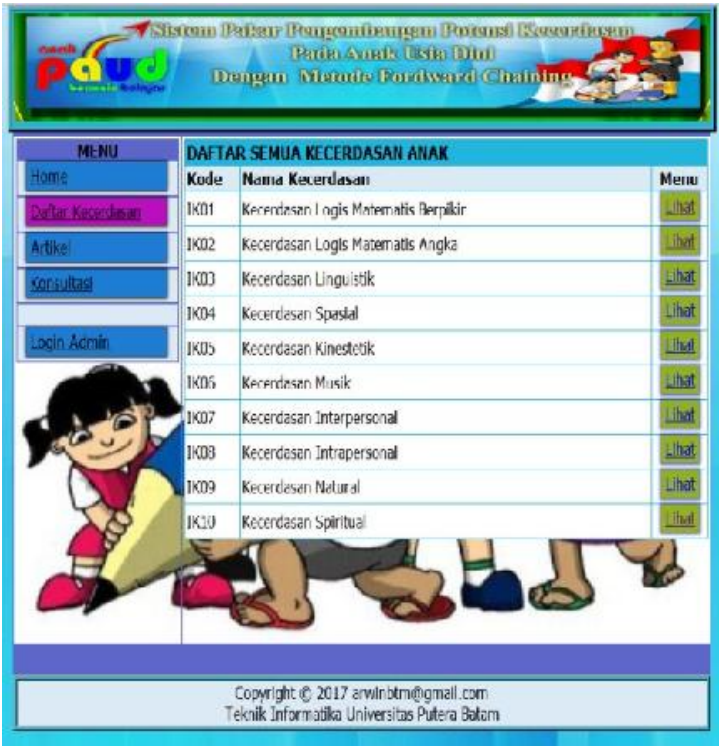

Gambar 4.5. Daftar Kecerdasan

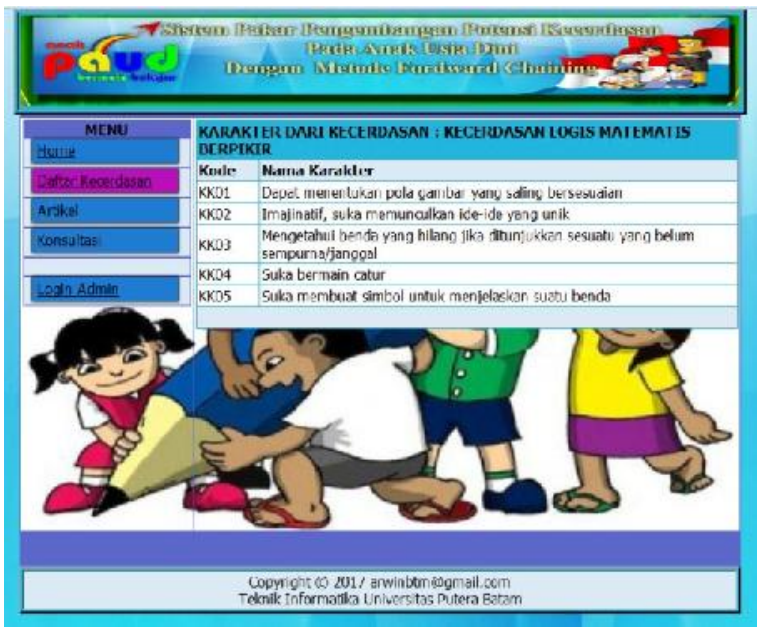

Gambar 4.6. Daftar Karakter diawali tentang defenisi dari Pendidikan Anak usia Dini (PAUD), kemudian kecerdasan 1 sampai dengan kecerdasan 10.

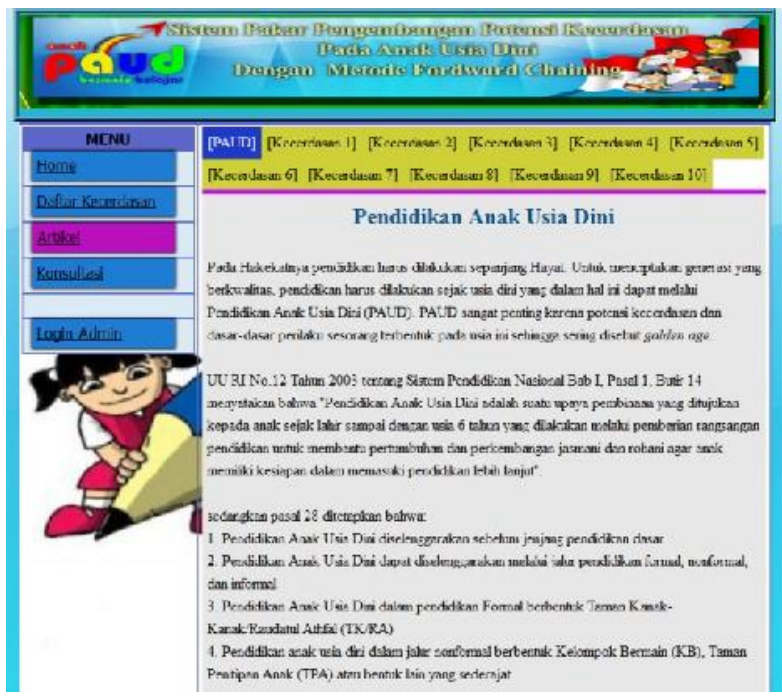

\section{Gambar 4.7. Artikel}

\section{Menu Konsultasi}

Menu Konsultasi digunakan oleh pengguna untuk melakukan konsultasi dalam mengetahui potensi kecerdasan yang dimiliki oleh anak khususnya anak usia dini. Sebelum melakukan konsultasi pengguna harus mengisi telebih dahulu data pengguna dan data anak melalui form pendaftaran yang ditampilkan sistem.

\section{Menu Artikel}

Menu Artikel berisikan informasi tentang potensi kecerdasan yang dimiliki anak usia dini. Informasi ini berfungsi untuk memberi wawasan dan pengetahuan bagi pengguna tentang potensi kecerdasan. Artikel 


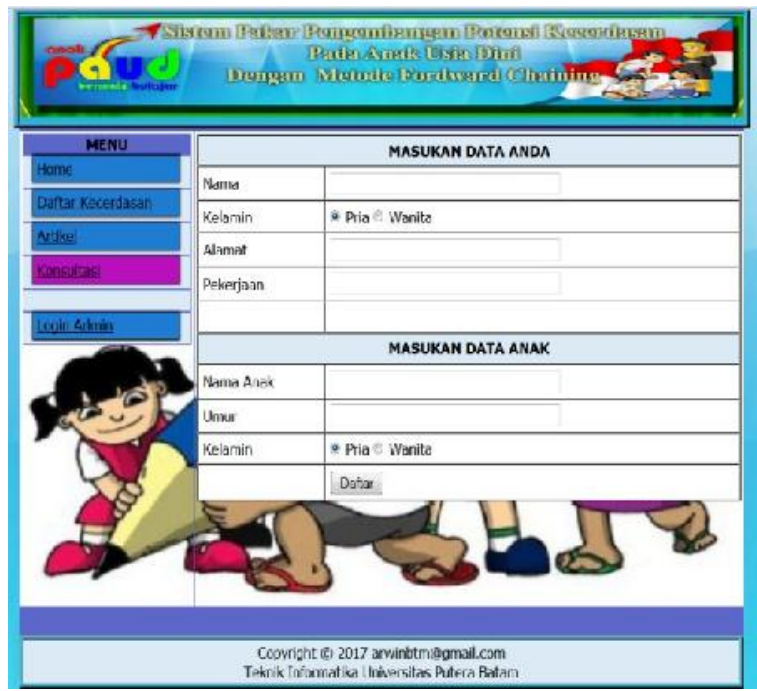

Gambar 4.8. Menu Pendaftaran User

Jika ada salah satu form tidak di isi maka sistem akan memerikan pesan kepada pengguna untuk melengkapi pengisian form tersebut.

\begin{tabular}{|l|l|}
\hline \multicolumn{3}{|c|}{ MASUKAN DATA ANDA } \\
\hline Nama & ARWIN \\
\hline Kelamin & o Pria O Wanita \\
\hline Alamat & Perum Rumi Sakinah Rink Marwah 2 No \\
\hline Pekerjaan & \multicolumn{2}{|c|}{ MASUKAN DATA ANAK } \\
\hline & fira \\
\hline Nama Anak & 2tahun \\
\hline Umur & e Pria O Wanita \\
\hline Kelamin & Dattar \\
\hline
\end{tabular}

Gambar 4.9. Menu Pesan Kesalahan Form Pendaftaran

Jika pengguna telah melakukan pengisian form yang ditampilkan, maka sistem akan menampilkan form konsultasi.
Pada form ini pengguna akan diberikan beberapa pertanyaan dengan hanya menjawab "Benar(Ya)" atau "Salah (Tidak)".

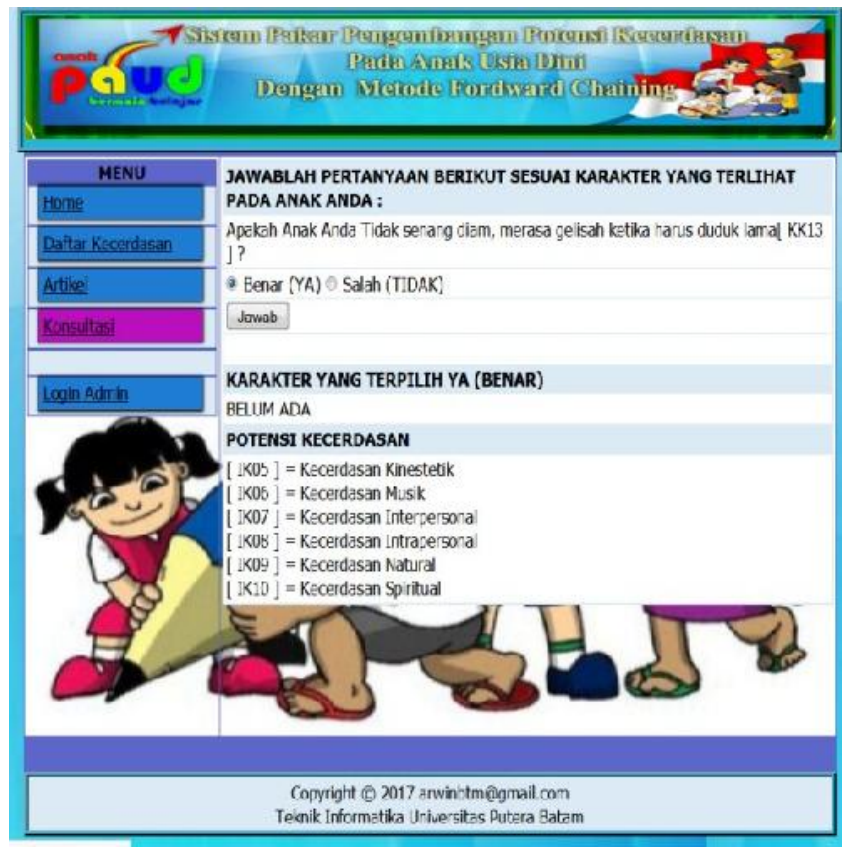

Gambar 4.10. Menu Pertanyaan

Setiap jawaban "Benar(Ya)" atau Salah (Tidak)" yang diberikan oleh penggunan, maka sistem akan membaca aturan-aturan (kaidah/fakta) untuk mencari aturan yang cocok dengan jawaban yang telah diberikan pengguna. Jika ada aturan yang cocok, maka sistem akan membaca aturan dan mencocokannya kembali. Dari hasil pencocokan akan didapatkan kesimpulan. Proses inferensi yang digunakan dalam sistem ini adalah pelecakan kedepan (forward Chaining). Pengguna juga dapat melakukan cetak hasil konsultasi tersebut. 


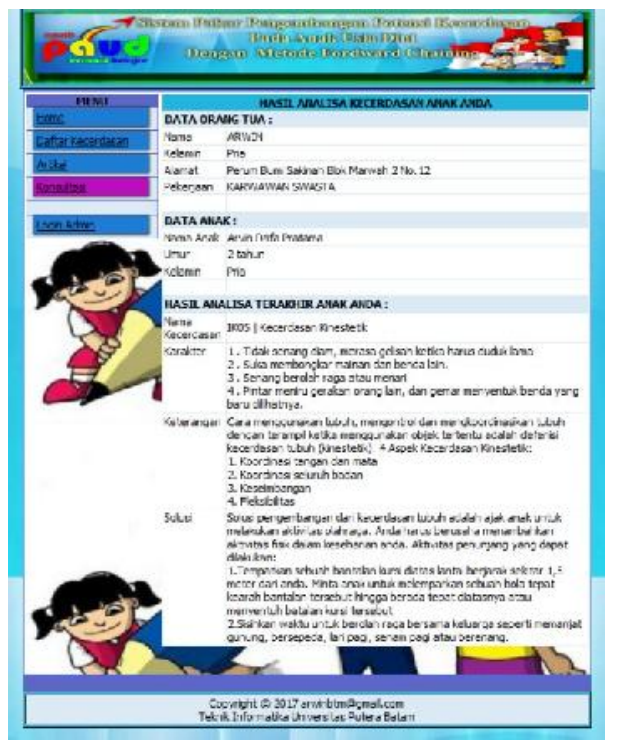

Gambar 4.11. Menu Hasil Konsultasi

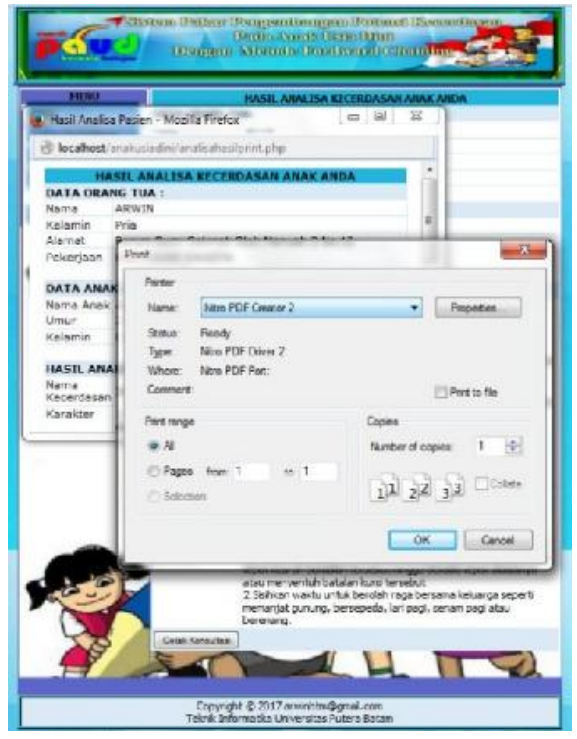

Gambar 4.12. Menu Cetak Hasil

Konsultasi

\section{SIMPULAN DAN SARAN}

\section{Simpulan}

Dari berbagai penjelasan, pembahasan, dan percobaan yang telah dilakukan pada
Sistem Pakar Pengembangan Potensi Kecerdasan Pada Anak Usia Dini Berbasis Web Dengan Metode Forward Chaining, maka didapatkan kesimpulan sebagai berikut:

1. Sistem Pakar yang telah dirancang adalah sistem pakar berbasis web dengan metode forward chaining yang dapat digunakan untuk pengembangan potensi kecerdasan pada anak usia dini sesuai dengan karakternya.

2. Sistem pakar yang telah dibangun adalah sistem pakar berbasis web yang dapat memberikan informasi mengenai mengenai potensi kecerdasan yang dimiliki anak usia dini serta cara pembimbingannya

3. Penerapan sistem pakar berbasis web yang telah dibangun menggunakan web browser seperti internet exploler, Mozilla Firefox, Google Chrome dan lain-lain. Interaksi sistem dengan pengguna melalui beberapa pertanyaan yang diajukan oleh sistem dan pengguna diminta memberikan jawaban "Benar(YA)" atau "Salah(Tidak)". Pertanyaan yang diberikan berupa karakter pada anak yang dapat dilihat dari kehidupan sehari-harinya. Setiap jawaban yang diberikan oleh pengguna, maka sistem akan membaca aturan-aturan (kaidah/fakta) untuk mencari aturan yang cocok dengan jawaban yang telah diberikan pengguna. Dari hasil 
pencocokan akan didapatkan sebuah kesimpulan.

\section{Saran}

Setelah melakukan penelitian dan membangun sistem pakar ini, ada beberapa saran yang penulis sampaikan guna pengembangan lebih lanjut:

1. Basis Pengetahuan sistem pakar pengembangan potensi kecerdasan pada anak usia dini kiranya dapat semakin diperkaya dengan penambahan indikator kecerdasan dan karakter setiap indikator kecerdasan tersebut.

2. Interface konsultasi pengguna dengan sistem disajikan berupa tanya jawab dapat dikembangkan dalam bentuk gambar/grafik atau interface yang lebih canggih dilengkapi dengan percakapan (Voice Communication).

3. Penelitian selanjutnya dapat menggunakan metode backward chaining atau 2 metode sekaligus yaitu forward chaining dan backward chaining atau metode lainnya pada sistem pakar untuk dapat membandingkan keakuratan kesimpulan yang dihasilkan pada setiap metode.

\section{DAFTAR PUSTAKA}

Daeli, F. (2013). Sistem Pakar Dalam Menentukan Tingkat IQ Anak Yang
Mengalami Reterdasi Mental Dengan Metode Certainty Factor (Studi Kasus : Pendidikan SLB / B Karya Murni ), Pelita Informatika Budi Darma. IV(3), 43-47.

E-Media Solusindo. (2008). Cara Gampang Membuat Website Dengan Joomla Untuk Pemula. Elex Media Komputindo Jakarta

Gordon, C., \& Huggins-Cooper, L. (2013). Meningkatkan 9 Kecerdasan Anak. Bhuana Ilmu Populer Jakarta.

Habibi, M. M. (2015). Analisis Kebutuhan Anak Usia Dini Buku Ajar S1 PAUD. Edisi Pertama. Deepublish Yogyakarta. Hamdi, A. S., \& Baharuddin, E. (2014). Metode Penelitian Kuantitatif Aplikasi Dalam Pendidikan. Edisi Pertama. Deepublish Yogyakarta

Hartati, S., \& Iswanti, S. (2008). Sistem Pakar dan Pengembangannya. Edisi Pertama. Graha Ilmu Yogyakarta.

Hayadi, B. H. (2016). Sistem Pakar Penyelesaian Kasus Menentukan Minat Baca, Kecenderungan, dan Karakter Siswa dengan Metode Forward Chaining. Edisi Pertama. Deepublish Yogyakarta.

Husda, N. E. (2012). Pengantar Teknologi Informasi. Edisi Pertama. Badouse Media Jakarta.

Kurnialensya, T., \& Syukur, A. (2013). Klasifikasi Penyakit Hipertensi 
Menggunakan Fuzzy Inferency System Dengan Menggunakan Metode Tsukamoto, Jurnal Teknologi Infromasi, 9(2), 62-69.

Kurniawan, D., \& Java Creativity. (2010). 145

Freeware pilihan untuk berbagai kebutuhan. Elex Media Komputindo Jakarta.

Kusrini. (2008). Aplikasi Sistem Pakar Menentukan Faktor Kepastian

Pengguna Dengan Metode Kuantifikasi

Pertanyaan. Edisi Pertama. Andi Yogyakarta.

Patilima, H. (2011). Metode Penelitian Kualitatif . Edisi Revisi. Alfabet Bandung.

Pramusti, A. \& Krisnawati. (2013).

Membangun Aplikasi Sistem Pakar Psikologis Klinis Pada Remaja Berbasis Android ( Studi Kasus: Puskesmas Seyegan ). Jurnal Ilmiah DASI. 14(04), 5-9.

Rosa A.S, dan M. S. (2011). Rekayasa Perangkat Lunak (Terstruktur dan Berorientasi Objek). Informatika Bandung.

Rosnelly, R. (2012). Sistem Pakar konsep dan Teori. Edisi Pertama. Andi Yogyakarta. Salisah, F. N., Lidya, L., Defit, S. (2015). Sistem Pakar Penentuan Bakat Anak Dengan Menggunakan Metode Forward Chaining. Jurnal Rekayasa dan
Manajemen Sistem Informasi, 1(1), 6266.

Saputra, A. (2012). Web Tips PHP, HTML5 dan CSS3. Jasakom Jakarta.

Sudaryono. (2015). Metodologi Riset di Bidang TI. Edisi Pertama. Andi Yogyakarta.

Suyanto. (2014). Artificial Intelligence. Revisi Kedua. Informatika Bandung.

Tim Pengembangan Ilmu Pendidikan. (2007). Ilmu \& Aplikasi Pendidikan. Edisi Pertama. Imperial Bhakti Utama Bandung.

Triandini, E., \& Suardika, I. Gede. (2012). step by step Desain Proyek Menggunakan UML. Edisi Pertama. Andi Yogyakarta.

Wibhowo, C., \& Sanjaya, R. (2011). Stimulasi Kecerdasan Anak Menggunakan Teknologi Informasi. Elex Media Komputindo Jakarta.

Wijaya, D. M., \& Raharja, W. K. (2015). Implementasi Metode Forward Chaining Pada Sistem Pakar Penentuan Karakter Diri Berbasis Website Menggunakan Framework Codeigniter, Prosiding PESAT, 6, P14-P20.

Zaki, A. (2008). PHP dan MySQL. Elex Media Komputindo Jakarta.

Zamroni, M. R., Cahyanti, C. A., Jalaluddin, A. (2013). Sistem Pakar Perkembangan Anak Usia 0-12 Bulan Berbasis Web 
ISSN : 2407-0491

Jurnal Edik Informatika E-ISSN : 2541-3716

Penelitian Bidang Komputer Sains dan Pendidikan Informatika

V4.i2(53-71) 2018

Dengan Metode Forward Chaining,

Jurnal Teknika, 5(2), 507-512.

71 Diterbitkan Oleh Program Studi Pendidikan Informatika STKIP PGRI Sumbar 